Research Article

\title{
Economic Design of EWMA Control Charts with Variable Sampling Intervals for Monitoring the Mean and Standard Deviation under Preventive Maintenance and Taguchi's Loss Functions
}

\author{
Li Xue $\mathbb{D D}^{1,2}$ and Zhen $\mathrm{He}^{1}$ \\ ${ }^{1}$ College of Management and Economics, Tianjin University, Tianjin 300072, China \\ ${ }^{2}$ School of Management Engineering, Zhengzhou University of Aeronautics, Zhengzhou 450046, China \\ Correspondence should be addressed to Li Xue; xuelitt@hotmail.com
}

Received 17 November 2020; Revised 13 June 2021; Accepted 23 July 2021; Published 8 September 2021

Academic Editor: Kauko Leiviskä

Copyright ( $\odot 2021 \mathrm{Li}$ Xue and Zhen He. This is an open access article distributed under the Creative Commons Attribution License, which permits unrestricted use, distribution, and reproduction in any medium, provided the original work is properly cited.

\begin{abstract}
The control chart and the maintenance management need to control process quality and reduce out-of-control cost. They are two key tools in the production process; however, they have usually been analyzed separately in the literature. Moreover, the existing studies integrating these two concepts suffer from three significant drawbacks as follows: (1) using control charts with fixed parameters to monitor the process, so that the small and middle shifts are detected slowly; (2) monitoring the mean and standard deviation separately, whereas, in real condition, the mean and standard deviation should be monitored simultaneously; (3) quality loss function is not usually used to design economic model, which leads to a large social quality loss in the monitoring process of control chart. To eliminate these weaknesses, the economic design of the exponential weighted moving average (EWMA) control chart with variable sampling intervals (VSI) for monitoring the mean and standard deviation under preventive maintenance and Taguchi's loss functions is proposed. The optimal values of the parameters are determined to minimize the loss-per-item in an average cycle process. In addition, a genetic algorithm is used in a numerical example to search for the optimal values of the parameters. According to the sensitivity analysis, the effect of the model parameters on the solution of the economic model is obtained. Finally, the comparison study shows that the VSI EWMA control charts designed by the joint economic model are expected to reduce loss.
\end{abstract}

\section{Introduction}

There are two key tools for controlling production processes-statistical process control (SPC) and maintenance management (MM). Although these two tools arise from different research areas, their common goal is to improve product quality and reduce cost by eliminating variances in the manufacturing process. SPC is a powerful tool consisting of different types of control charts for monitoring the process, and it can be ensured that the quality characteristics of a product are at the nominal or required levels [1]. However, the control chart always neglects type II error, in which the control chart does not trigger a signal when the process is out-of-control. Therefore, it will cause too high and avoidable costs on the process [2]. Maintenance in industrial situations is considered an important factor contributing to reducing production costs and increasing productivity. One way to decrease type II error and the cost for detecting the out-of-control signal is to combine the control charts with the maintenance management technique. This work is closely related to several research fields, including economic design of control charts, adaptive control charts, integration of control chart and maintenance management, and quality loss function. The existing literatures of such researches are reviewed briefly in the following.

To reduce the cost of process control, Duncan [3] first proposed the economic model to determine the three test 
parameters in the $\mathrm{X}$-bar control chart, so that the average cost can be minimized when a single assignable cause occurs. Montgomery [4] gave a thorough review of the literature in the economic designs domain. Lorenzen and Vance [5] presented a framework of economic design for the control charts. Since then, considerable attention has been devoted to the optimal economic determination of the three parameters of X-bar charts [6]. Subsequently, many scholars have studied the economic design of various control charts. Franco et al. [7] developed an economic model of Shewhart control charts for monitoring autocorrelated data with skip sampling strategies; Naderkhani and Makis [8] investigated the economic design of multivariate Bayesian control chart with two sampling intervals; Costa [9] investigated the Economic statistical design of ARMA control chart through a modified fitness-based self-adaptive differential evolution. Here, we briefly review some researches on the economic design of EWMA control charts. To consider the uncertainty among the cost and process parameters in practice, Amiri et al. [10] developed a process monitoring strategy based on the robust economic and economic-statistical design of the EWMA control chart. Considering measurement error and taking multiple measurement errors, as well as linear and quadratic Taguchi loss function of poor quality products, Saghaei et al. [11] proposed the economic model of EWMA control charts. Chou et al. [12] developed the economic design of the VSI EWMA control chart to determine the values of the six test parameters of the charts, such that the expected total cost is minimized. They assumed that the measurements in each sampled subgroup are normally distributed, but this assumption is not always true in practice.

In the case of the nonnormal behavior of measurements, Xue and Liu [13] used Burr distribution to approximate various nonnormal distributions and developed an economic model of the VSI EWMA control chart. In addition, many scholars have studied the economic design of nonparametric control chart. Li et al. [14] proposed an economic model based on the Duncan-type cost function for designing a nonparametric sign chart for monitoring the location parameter of a univariate process. When true process location parameter is unknown, Li et al. [15] developed an economically designed nonparametric control chart for monitoring unknown location parameter based on the Wilcoxon rank-sum (hereafter WRS) statistic. Li and Mukherjee [16] presented two distribution-free cost-efficient Shewhart-type schemes for sequentially monitoring process location with restricted false alarm probability, based, respectively, on the Sign and Wilcoxon rank-sum statistics. Li and Mukherjee [17] proposed two economically optimized nonparametric schemes for monitoring process variability based on two popular two-sample rank statistics for differences in scale parameters, known as the Ansari-Bradley statistic and the mood statistic. In addition to the above research, many scholars have carried out the economic design and reliability group of the sampling plan, for example [18-23].

With the development of automation and mechanization, many automatic techniques can be applied to production. Thus, the status of equipment plays an increasingly important role in controlling quantity, quality, and cost. Although academia and industry have long recognized the close relationship between equipment maintenance and process quality, research on the integration and association between equipment maintenance decisions and process quality control decisions has not attracted widespread attention from relevant scholars until recently [24-27]. In this regard, Linderman et al. [28] constructed a generalized analytic model that incorporates statistical process control and maintenance policy to minimize total expected cost. Zhou and Zhu [29] developed a joint model that integrates the maintenance activities with the design of control charts. They claimed that integrated models perform better than the two stand-alone models. Xiang [30] developed an integrated model of statistical process control and preventive maintenance for a manufacturing process that deteriorates according to a discrete-time Markov chain approach. Shrivastava et al. [31] presented an integrated model for joint optimization of preventive maintenance and quality control policy with cumulative sum (CUSUM) control chart parameters. Bouslah et al. [32] researched the joint economic design of production, continuous sampling inspection, and preventive maintenance of a deteriorating production system. Salmasnia et al. [33] developed an integrated model of economic production quantity, statistical process monitoring, and maintenance in the presence of multiple assignable causes. The particle swarm optimization algorithm (PSO) is used to minimize the expected total cost per production cycle, subject to statistical quality constraints. Wan et al. [34] developed an integrated model of $\mathrm{MM}$ and quality control policy with an adaptive synthetic chart, and the corrective maintenance and preventive maintenance were considered in that paper.

Although the research on joint optimization of preventive maintenance and control charts has made great progress, most of the previous research is about the invariance control chart, which means that the parameters are not unfixed. However, to improve the performance of detecting small and moderate shifts, different types of adaptive control charts such as variable sampling intervals (VSI), variable sample sizes (VSS), and variable parameters (VP), in which the design parameters are adaptive depending on the position of previous observation on the chart, have developed in recent years [35-43]. The research results have shown that the efficiency of the adaptive control chart over the traditional control charts, in which the parameters are constant. On the other hand, the mean and standard deviation usually were monitored by a control chart separately. However, the mean and standard deviation should be monitored using one kind of control chart simultaneously in real condition. In order to improve the efficiency of control chart monitoring small shifts, EWMA control charts for monitoring the process mean and standard deviation jointly with variable sampling intervals were constructed [44].

The concept of quality loss function was proposed by Taguchi firstly. Due to the high measurement cost, the mass quality loss function has been widely used. It focuses on the 
loss caused by the deviation of the mass output from the target value. If a characteristic measurement is equal to the target value, the loss is zero, but the further far away from its target value, the greater the quality loss. Therefore, the output characteristics should be as close to their target values as possible. Taguchi suggests using the quality loss function to measure the loss caused by the deviation of the output characteristic of the qualified product from the target value. This concept has also been used in some models of economic design of control charts $[45,46]$. In addition, Sultana et al. [47] develop an economic statistical design of the (EWMA) chart using variable sampling interval at fixed times (VSIFT) control scheme considering preventive maintenance and Taguchi loss function. They considered the possibility of an equipment failure in terms of machine breakdown or improper functioning of the equipment, which results in poor product quality and call for maintenance action, to study the linkage between declining performance of a machine and process. In particular, machine failures are divided into two failure modes in their study: (1) failure mode 1 (FM1) leads to immediate breakdown of the machine. (2) Failure mode 2 (FM2) leads to reduction in process quality owing to shifting of the process mean. Their study mainly monitors the shift of process mean and does not consider monitoring the shift of process mean and standard deviation at the same time. Besides, they do not focus on the determination of a warning limit or fixed time interval beyond which planned maintenance will be carried out.

To bridge the existing gaps in the literature, a novelty mathematical optimization model that integrates the concepts of quality loss, maintenance policy, and designing the control chart is proposed in this study. The main contributions of this study can be summarized as follows: (1) this study integrates the concepts of control charts, maintenance management, and quality loss function. It mainly considers preventive maintenance in one cycle but does not consider downtime maintenance; (2) the mean and standard deviation can be monitored simultaneously by EWMA control chart; (3) the variable sampling interval schemes should be applied to improve the monitoring efficiency of control chart. Therefore, in this paper, the economic design of the VSI EWMA control chart for monitoring the process mean and standard deviation based on Taguchi's loss function and preventive maintenance is investigated. Six test parameters of the chart (i.e., the sample size, the long sampling interval, the short sampling interval, the control limit coefficient, the warning limit coefficient, and the exponential weight constant) are determined by minimizing the total loss. A numerical example is used to illustrate how the model works and to demonstrate its use.

\section{VSI EWMA Control Charts for Monitoring the Mean and Standard Deviation}

Before the economic model of VSI EWMA control charts is established, we first introduce the VSI EWMA control charts for monitoring the mean and standard deviation. The details of the approach are shown as follows.
Assume that the observations $Y$ are followed by the normal distribution with mean $\mu$ and standard deviation $\sigma$. When the process is in control, $\mu=\mu_{0}, \sigma=\sigma_{0}$. Meanwhile, when the process is on out-of control, $\mu=\mu_{0}+\delta_{1} \sigma_{0}$, or, $\sigma=\delta_{2} \sigma_{0}$, where $\delta_{1}$ and $\delta_{2}$ are constants, and typically $\delta_{2}$ is larger than 1. Let $X_{i 1}, X_{i 2}, \ldots, X_{i n}$ be the $i$ th sample, which the sample size is $n$, and then $\overline{X_{i}}=(1 / n) \sum_{j=1}^{n} X_{i j}$ is the sample mean of the $i$ th sample, and $S_{i}^{2}=(1 /(n-1)) \sum_{j=1}^{n}\left(X_{i j}-\overline{X_{i}}\right)^{2}$ is the sample variance of the $i$ th sample. Then, the statistic of Semicircle (SC) chart is defined as [48]

$$
T_{i}=\left(\overline{X_{i}}-\mu_{0}\right)^{2}+\frac{n-1}{n} S_{i}^{2}, \quad i=1,2, \ldots
$$

Let $T_{i}^{*}=\left(n / \sigma_{0}^{2}\right) T_{i}$. When the process is in control, $T_{i}^{*} \sim \chi_{n}^{2}$, so we can get the mean and variance of $T_{i}^{*}$ as follows:

$$
\begin{aligned}
E\left(T_{i}^{*}\right) & =n, \\
\operatorname{Var}\left(T_{i}^{*}\right) & =2 n .
\end{aligned}
$$

Then, the ith sample statistic of EWMA chart for monitoring the mean and standard deviation is defined as [49]

$$
Q_{i}=(1-\lambda) Q_{i-1}+\lambda T_{i}^{*}, \quad i=1,2, \ldots,
$$

where $\lambda$ is the exponential weight constant, and $0<\lambda \leq 1$, and the starting value $Q_{0}$ is set to be $n$ [49].

According to equations (2) and (3), we can get the mean and variance of $Q_{i}$ as follows:

$$
\begin{aligned}
E\left(Q_{i}\right) & =E\left(T_{i}^{*}\right)=n, \\
\operatorname{Var}\left(Q_{i}\right) & =\frac{\lambda}{(1-\lambda)}\left[1-(1-\lambda)^{2 t}\right] \operatorname{Var}\left(T_{i}^{*}\right) \\
& =\frac{2 n \lambda}{(1-\lambda)}\left[1-(1-\lambda)^{2 t}\right] .
\end{aligned}
$$

When $t$ is getting larger, $\operatorname{Var}\left(Q_{i}\right)$ will approach the steady-state value. Equation (5) will become

$$
\operatorname{Var}\left(Q_{i}\right) \approx \frac{2 n \lambda}{(1-\lambda)}, \quad 0<\lambda \leq 1 .
$$

Because $Q_{i} \geq 0$, the upper control limits UCL and the upper warning limits UWL can be decided.

$$
\begin{aligned}
\mathrm{UCL} & =E\left(Q_{i}\right)+k \sqrt{\operatorname{Var}\left(Q_{i}\right)}=n+k \sqrt{\frac{2 n \lambda}{2-\lambda}}, \\
\mathrm{UWL} & =n+w \sqrt{\frac{2 n \lambda}{2-\lambda}},
\end{aligned}
$$

where $k$ is the control limit coefficient of the VSI EWMA chart, $w$ is the warning limit coefficient of the VSI EWMA chart, and $0<w<k$.

The in-control region of the control chart is divided into two parts, including the safe region and the warning region. Let $h_{1}$ and $h_{2}$ be the long sampling interval and the short 
sampling interval, respectively. If the sample statistic falls in the safe region (i.e., $0 \leq Q_{i} \leq \mathrm{UWL}$ ), then take the next sample using the sampling interval $h_{1}$. If the sample statistic falls in the warning region (i.e., $\mathrm{UWL}<\mathrm{Q}_{i} \leq \mathrm{UCL}$ ), then take the next sample using the sampling interval $h_{2}$. If the sample statistic falls outside the control limits (i.e., $Q_{i}>\mathrm{UCL}$ ), then we will find the assignable cause.

\section{Development of Cost Function}

To develop the cost function, some assumptions should be made as follows:

(1) The process is assumed to be in-control $\left(\mu=\mu_{0}, \sigma=\sigma_{0}\right)$ initially

(2) The process will be disturbed by a single assignable cause that causes a fixed shift in the process $\left(\mu=\mu_{0}+\delta_{1} \sigma_{0}, \sigma=\delta_{2} \sigma_{0}\right)$

(3) The time between occurrences of the assignable causes is exponential with a mean of $\theta$ occurrences per hour

(4) Once the process goes out of control, it remains out of control until being detected and corrected

(5) The process shift is instant and cannot automatically be brought back to an in-control state

(6) Preventive maintenance will be conducted when the statistic $Q_{i}$ falls in the warning region

The expected cycle length is defined as the time span from the beginning of an in-control state to the next incontrol state. In each production cycle, once an assignable cause occurs, it can be detected and identified. After that, the process will be brought back to the in-control process condition. The production cycle length can be divided into four-time intervals: in-control period $T_{1}$; out-of- control period starting from the occurrence of an assignable cause to the control chart signals, denoted as $T_{2}$; the time period for identifying and correcting the assignable cause $T_{3}$, and the time period for sampling, inspecting, evaluating, and plotting the subgroup result $T_{4}$.

\subsection{The Average Cycle Length}

(1) The expected length of the in-control period can be written as

$$
T_{1}=\frac{1}{\theta}+\frac{\left(1-\gamma_{1}\right) s t_{0}}{\operatorname{ANSS}_{0}}
$$

where $t_{0}$ is expected search time when the signal indicates a false alarm, ANSS $_{0}$ is the in-control average run length, and $s$ is the expected number of samples taken when the process is in control and can be calculated by [12]

$$
s=\frac{e^{-\theta h_{0}}}{1-e^{-\theta h_{0}}} \approx \frac{1}{\theta h_{0}},
$$

$\gamma_{1}= \begin{cases}1, & \text { if production continues during searches, } \\ 0, & \text { if production ceases during searches. }\end{cases}$ Note that $h_{0}$ can be expressed as

$$
h_{0}=\frac{\mathrm{ATS}_{0}}{\mathrm{ANSS}_{0}},
$$

where $\mathrm{ATS}_{0}$ is the in-control average time to signal.

(2) The out-of-control period before the last sample of the detecting subgroup is taken can be expressed as

$$
T_{2}=\mathrm{ATS}_{1}-\tau,
$$

where $\mathrm{ATS}_{1}$ is the out-of-control average time to signal, and $\tau$ is the expected time of occurrence of the assignable cause between two samples when the process is in control. It can be shown that [12]

$$
\tau=\frac{1-\left(1+\theta h_{0}\right) e^{-\theta h_{0}}}{\theta\left(1-e^{-\theta h_{0}}\right)} \approx \frac{h_{0}}{2}-\frac{1}{12} \theta h_{0}^{2} .
$$

(3) The time period for conducting preventive maintenance is equal to

$$
T_{3}=\left(p_{01} \times \frac{T_{1}}{h_{0}}+p_{11} \times \frac{T_{2}+n g+\gamma_{1} t_{1}+\gamma_{2} t_{2}}{h_{0} /}\right) \times T_{P} .
$$

(4) The time period for identifying and correcting the assignable cause is equal to

$$
T_{4}=t_{1}+t_{2}
$$

where $t_{1}$ is the expected time to identify the assignable cause, and $t_{2}$ is the expected time to correct the assignable cause $\left(T_{P}<t_{2}\right)$.

(5) Define $g$ as the average sampling, inspecting, evaluating, and plotting time for each sample. The time period for sampling, inspecting, evaluating, and plotting the subgroup result is

$$
T_{5}=n g \text {. }
$$

According to equations (8), (11), (13)-(15), therefore, the average cycle length can be obtained:

$$
\begin{aligned}
T= & T_{1}+T_{2}+T_{3}+T_{4}+T_{5} \\
= & \frac{1}{\theta}+\frac{\left(1-r_{1}\right) s t_{0}}{\mathrm{ANSS}_{0}}+\mathrm{ATS}_{1}-\tau+t_{1}+t_{2}+n g \\
& +\left(p_{01} \times \frac{T_{1}}{h_{0}}+p_{11} \times \frac{T_{2}+n g+\gamma_{1} t_{1}+\gamma_{2} t_{2}}{h_{0} /}\right) \times T_{P} .
\end{aligned}
$$

3.2. The Cost Function. To reduce the quality loss of the production process, the concept of Taguchi's loss function can be applied to the economic design model of the VSI 
EWMA control chart for monitoring the mean and standard deviation in this section. Then, the expected loss cost generated in a cycle length includes several relevant costs, namely, (1) the loss cost of false detection of signal, sampling, inspecting, evaluating, plotting, and actually finding, repairing the assignable cause, (2) the preventive maintenance loss cost, (3) the social loss cost in control state, and finally (4) the social loss cost in the out of control state.

We denote $d$ as the average cost per false alarm, $W$ as the cost to locate and repair an assignable cause, $a$ as the fixed cost per sample, $b$ as the cost per unit sampled, and $d$ as the cost due to loss of a false detection of signal. If production continues during the correction process, $\gamma_{2}=1$, and if production ceases during the correction process, $\gamma_{2}=0$. Then, the cost of process sampling, inspecting, evaluating, plotting, and actually finding, repairing the assignable cause, can be shown as

$$
\begin{aligned}
L_{1}= & \frac{1}{\mathrm{ANSS}_{0}} \times \frac{T_{1}}{h_{0}} \times d+(a+b n) \\
& \times\left(\frac{T_{1}}{h_{0}}+\frac{T_{2}+n g+\gamma_{1} t_{1}+\gamma_{2} t_{2}}{h_{0} /}\right)+W,
\end{aligned}
$$

where $h_{0}$ is the expected sampling interval when the process is in-control, and $h_{0} /$ is the expected sampling interval when the process is out-of-control. $h_{0} /$ can be expressed as $h_{0} /=\left(\mathrm{ATS}_{1} / \mathrm{ANSS}_{1}\right)$.

If we let $C_{p m}$ be the average cost per preventive maintenance action, then the preventive maintenance cost can be expressed as

$$
L_{2}=C_{p m} \times\left[p_{01} \times \frac{T_{1}}{h_{0}}+p_{11} \times \frac{T_{2}+n g+\gamma_{1} t_{1}+\gamma_{2} t_{2}}{h_{0} /}\right],
$$

where $p_{01}$ is the probability that samples fall into the warning region when the process is in-control, and $p_{11}$ is the probability that samples fall into the warning region when the process is out-of-control, respectively. Denote the probability that the samples fall into the safe region when the process is in-control by $p_{00}$, and the probability that the samples fall into the safe region when the process is out-ofcontrol by $p_{10}$, respectively. Then $p_{01}$ and $p_{11}$ can be expressed as

$$
\begin{aligned}
& \left\{\begin{array}{l}
p_{00}+p_{01}=1-\frac{1}{\mathrm{ANSS}_{0}}, \\
h_{0}=h_{1} \times p_{00}+\left(h_{2}+Z\right) \times p_{01},
\end{array}\right. \\
& \left\{\begin{array}{l}
p_{10}+p_{11}=1-\frac{1}{\mathrm{ANSS}_{1}}, \\
h_{0} /=h_{1} \times p_{10}+\left(h_{2}+Z\right) \times p_{11} .
\end{array}\right.
\end{aligned}
$$

Suppose that the specification limit of a quality characteristic is $m \pm \Delta$, where $m$ is the target value. It will cost $M$ dollars to repair the item and bring the shifted process back to in-control state. Then, the value for the coefficient of loss function can be obtained by $\left(M / \Delta^{2}\right)$. Suppose that the process is still in-control. Let $\mathrm{d} v$ be the difference between the average and target, and let $\sigma$ be the standard deviation of the process. Then, the in-control average social loss can be expressed as

$$
L_{3}=\frac{M}{\Delta^{2}}\left(\sigma^{2}+(\mathrm{d} v)^{2}\right) \times T_{1} \times y,
$$

where $y$ is the production quantity per unit time.

If an assignable cause occurs, it will cause loss $M$ due to a greater percentage of items being outside the control limits.

$$
L_{4}=\frac{M}{\Delta^{2}}\left(\left(\delta_{2} \sigma\right)^{2}+\left(\delta_{1} \sigma+\mathrm{d} v\right)^{2}\right) \times\left(T_{2}+t_{1}+t_{2}+n g\right) \times y .
$$

Hence, from equations (17), (18), (20), and (21), the loss in an average cycle process is given by

$$
L=L_{1}+L_{2}+L_{3}+L_{4}
$$

From equations (16) and (22), the loss-per-item in an average cycle process is given by

$$
\mathrm{ETL}=\frac{L}{T}
$$

The economic design of the VSI EWMA control chart for monitoring the mean and standard deviation under preventive maintenance and Taguchi's loss functions can be determined by the optimal values of the eight test parameters $\left(n, h_{1}, h_{2}, k, w, \lambda\right)$ such that the loss-per-item in an average cycle process ETL is minimized.

\section{An Example and Solution Procedure}

From the examination of the probability components in equation (23), it can be seen that determining the economically optimal values of the six test parameters for the VSI EWMA control chart for monitoring the mean and standard deviation is not straightforward. To illustrate the nature of the solutions obtained from economic design of VSI EWMA control chart, a particular numerical example is provided.

A bearing factory produces various shapes of casting, so that the castings manufacturing process should be monitored by the VSI EWMA control chart. It is known that the diameter of casting approximately follows a normal distribution with a mean $\mu$ and standard variation $\sigma$. When the process is in control, $\mu=\mu_{0}=2.0, \sigma=\sigma_{0}=1$. When the process is out of control, $\mu=\mu_{1}=\mu_{0}+\delta_{1} \sigma_{0}$, $\sigma=\delta_{2} \sigma_{0}=1.5$. The cost and model parameters in this example are given as follows:

$$
\begin{aligned}
a & =\$ 1, \\
b & =\$ 0.5, \\
\Delta & =2, \\
W & =\$ 4, \\
d & =\$ 0.5,
\end{aligned}
$$




$$
\begin{aligned}
m & =2.5, \\
g & =0.2 \mathrm{hr}, \\
t_{1} & =0.5 \mathrm{hr}, \\
t_{2} & =0.5 \mathrm{hr}, \\
\theta & =0.01, \\
\gamma_{1} & =\gamma_{2}=1, \\
\delta_{1} & =1, \\
\delta_{2} & =1.5, \\
y & =10, \\
C_{p m} & =\$ 10, \\
M & =\$ 10 .
\end{aligned}
$$

The optimal design parameters $n, h_{1}, h_{2}, k, w, \lambda$ can be derived by minimizing the ETL. Because the expression of ETL is very complex, the general optimization method cannot be used. Although there are several kinds of numerical optimization methods, Genetic Algorithm (GA) has advantages in the following aspects: (1) it can be applied for different types of optimization problems; (2) it can avoid traps of the local optimum; (3) it can give the global optimum solution efficiently. Hence, the optimization problem can be solved using GA to get the optimal solution.

Using the GA toolbox in Matlab, we let population size $=20$; crossover probability $=0.8$; mutation rate $=0.1$; the number of generation $=100$; the fitness function is the cost model as shown in equation (23). The constraint conditions for each test parameter are set as follows: $1 \leq n \leq 30,1<h_{1}<3,0<h_{2}<1,0.001<k<4, \quad 0.001<w<$ $4, w<k, 0.001<\lambda<1$. After running the toolbox, we obtain the optimal values of $n, h_{1}, h_{2}, k, w, \lambda$ as follows: $n=2$, $h_{1}=2.5, \quad h_{2}=0.985, \quad k=2.097, \quad w=0.5, \quad \lambda=0.296$, $\mathrm{ETL}=17.3247$.

To compare the proposed control chart with the existing control chart, we get the optimal design parameters $n, h, k, \lambda$ of fixed sampling intervals EWMA control chart that considers quality loss and preventive maintenance by minimizing the ETL. The constraint conditions for each test parameter are set as follows: $1 \leq n \leq 30,1<h<$ $3,0.001<k<4,0.001<\lambda<1$. After running the toolbox, we obtain the optimal values of $n, h_{1}, h_{2}, k, w, \lambda$ as follows: $n=1, h=0.681, k=2.764, r=0.305, \mathrm{ETL}=18.852$. The result shows that the VSI EWMA control charts designed by the joint economic model have a less expected loss and are superior to the FSI EWMA control charts designed by the joint economic model.

\section{Sensitivity Analysis}

Using orthogonal-array experimental design and multiple regression method, a sensitivity analysis of the economic model of the VSI EWMA chart for monitoring the mean and standard deviation is conducted to study the effect of model parameters on the solution. The model parameters $\left(a, b, \theta, d, g, t_{1}, t_{2}, e, C_{p m}, W, M\right)$ are independent variables, and the six design parameters $\left(n, h_{1}, h_{2}, k, w, \lambda\right)$ and the lossper-item in an average cycle process ETL are dependent variables.

Independent variables (model parameters) and their corresponding level planning are shown in Table 1 . This is a trial with eleven factors and two levels, so the $L_{16}$ orthogonal array is employed, and there are 16 trials. For each trial, the genetic algorithm is applied to give the optimal solution of the economic design, with the following model parameters fixed: $\gamma_{1}=\gamma_{2}=1, t_{0}=1$. The 16 trials selected according to the orthogonal Table $L_{16}\left(2^{15}\right)$ are shown in Table 2, and the output of the genetic algorithm for each trial is recorded in Table 3.

To study the effect of model parameters on the solution of economic design of the VSI EWMA chart for monitoring the mean and standard deviation, the statistical software SPSS is used to run the regression analysis for each dependent variable with the significance level equal to 0.1 . From the output of SPSS with design parameters and lossper-item in an average cycle process ETL, we can obtain the model parameters that significantly impact the solution of the economic design of the VSI EWMA chart.

The SPSS output for sample size $n$ is presented in Table 4 . From the ANOVA in Table 4 (1), if the significance level is set to be 0.1 , there is one parameter affecting the sample size $n$ significantly at least. From the regression coefficients in Table 4 (2), we find that the cost per unit sampled $b$, the expected time to identify correct the assignable cause $t_{2}$, the average sampling, inspecting, evaluating, and plotting time for each sample $g$ and the average cost per preventive maintenance action $C_{p m}$ affect the sample size significantly. Since the coefficients are negative, the larger the four parameters, the larger the sample size.

The output of SPSS for the long sampling interval $h_{1}$ is recorded in Table 5. From the ANOVA in Table 5 (1), there is one parameter affecting the long sampling interval $h_{1}$ significantly at least. It can be seen from the regression coefficients in Table 5 (2) that five model parameters significantly affect the long sampling interval. An increase in the fixed cost per sample $a$ and the deviation of process standard deviation $\delta_{2}$ lengthen the long sampling interval, respectively. An increase in the average sampling, inspecting, evaluating, and plotting time for each sample $g$, the cost to locate and repair an assignable cause $W$ and the loss incurred by the nonconformity product $M$ negatively affect the long sampling interval.

Table 6 is the SPSS output for the short sampling intervals $h_{2}$. It can be seen from Table 6 (2) that five model parameters significantly affect the short sampling intervals. An increase in the average cost per preventive maintenance action $C_{p m}$, the expected time to identify the assignable cause $t_{1}$ and the expected time to correct the assignable cause $t_{2}$ lengthen the short sampling intervals, respectively. The cost per unit sampled $b$ and the cost to locate and repair an assignable cause $W$ negatively affect the short sampling interval. 
TABLe 1: Twelve model parameters and their lever panning.

\begin{tabular}{lcc}
\hline Model parameter & Lever 1 & Lever 2 \\
\hline$a$ & 1 & 4 \\
$b$ & 0.1 & 1 \\
$\theta$ & 0.01 & 0.05 \\
$d$ & 1 & 5 \\
$g$ & 0.1 & 0.5 \\
$t_{1}$ & 2 & 6 \\
$t_{2}$ & 2 & 6 \\
$\delta_{1}$ & 0.5 & 1 \\
$\delta_{2}$ & 1.2 & 2 \\
$W$ & 1 & 5 \\
$C_{p m}$ & 10 & 20 \\
$M$ & 5 & 10 \\
\hline
\end{tabular}

TABLE 2: 16 trials selected according the orthogonal trial $L_{16}\left(2^{15}\right)$.

\begin{tabular}{lcccccccccccc}
\hline \multirow{1}{*}{ Trial } & & \multicolumn{1}{c}{ Model parameter } \\
& $a$ & $b$ & $\theta$ & $d$ & $g$ & $t_{1}$ & $t_{2}$ & $\delta_{1}$ & $\delta_{2}$ & $W$ & $C_{p m}$ & $M$ \\
\hline 1 & 1 & 0.1 & 0.01 & 1 & 0.1 & 2 & 2 & 0.5 & 1.2 & 1 & 10 & 5 \\
2 & 1 & 0.1 & 0.01 & 1 & 0.1 & 2 & 2 & 1.0 & 2.0 & 5 & 20 & 10 \\
3 & 1 & 0.1 & 0.01 & 5 & 0.5 & 6 & 6 & 0.5 & 1.2 & 1 & 10 & 10 \\
4 & 1 & 0.1 & 0.01 & 5 & 0.5 & 6 & 6 & 1.0 & 2.0 & 5 & 20 & 5 \\
5 & 1 & 1.0 & 0.05 & 1 & 0.1 & 6 & 6 & 0.5 & 1.2 & 5 & 20 & 5 \\
6 & 1 & 1.0 & 0.05 & 1 & 0.1 & 6 & 6 & 1.0 & 2.0 & 1 & 10 & 10 \\
7 & 1 & 1.0 & 0.05 & 5 & 0.5 & 2 & 2 & 0.5 & 1.2 & 5 & 20 & 10 \\
8 & 1 & 1.0 & 0.05 & 5 & 0.5 & 2 & 2 & 1.0 & 2.0 & 1 & 10 & 5 \\
9 & 4 & 0.1 & 0.05 & 1 & 0.5 & 2 & 6 & 0.5 & 2.0 & 1 & 20 & 5 \\
10 & 4 & 0.1 & 0.05 & 1 & 0.5 & 2 & 6 & 1.0 & 1.2 & 5 & 10 & 10 \\
11 & 4 & 0.1 & 0.05 & 5 & 0.1 & 6 & 2 & 0.5 & 2.0 & 1 & 20 & 10 \\
12 & 4 & 0.1 & 0.05 & 5 & 0.1 & 6 & 2 & 1.0 & 1.2 & 5 & 10 & 5 \\
13 & 4 & 1.0 & 0.01 & 1 & 0.5 & 6 & 2 & 0.5 & 2.0 & 5 & 10 & 5 \\
14 & 4 & 1.0 & 0.01 & 1 & 0.5 & 6 & 2 & 1.0 & 1.2 & 1 & 20 & 10 \\
15 & 4 & 1.0 & 0.01 & 5 & 0.1 & 2 & 6 & 0.5 & 2.0 & 5 & 10 & 10 \\
16 & 4 & 1.0 & 0.01 & 5 & 0.1 & 2 & 6 & 1.0 & 1.2 & 1 & 20 & 5 \\
\hline
\end{tabular}

TABLE 3: Outputs of the genetic algorithm for each trial.

\begin{tabular}{lccccccc}
\hline \multirow{2}{*}{ Trial } & & \multicolumn{7}{c}{ Output } \\
& $n$ & $h_{1}$ & $h_{2}$ & $k$ & $w$ & $\lambda$ & ETL \\
\hline 1 & 9 & 2.500 & 0.272 & 2.647 & 1.361 & 0.594 & 18.3545 \\
2 & 3 & 2.487 & 0.123 & 3.185 & 0.962 & 0.997 & 38.8650 \\
3 & 2 & 1.714 & 0.530 & 2.383 & 0.789 & 0.683 & 38.6429 \\
4 & 2 & 2.051 & 0.739 & 3.946 & 1.160 & 0.573 & 25.5207 \\
5 & 1 & 2.053 & 0.441 & 2.103 & 0.629 & 0.699 & 25.5298 \\
6 & 2 & 2.499 & 0.295 & 2.001 & 0.418 & 0.868 & 83.3284 \\
7 & 2 & 1.361 & 0.157 & 2.533 & 1.193 & 0.721 & 46.5759 \\
8 & 2 & 2.485 & 0.101 & 3.025 & 0.896 & 0.772 & 32.7368 \\
9 & 3 & 2.500 & 0.784 & 3.092 & 0.596 & 0.915 & 35.9818 \\
10 & 3 & 1.792 & 0.334 & 2.575 & 0.578 & 0.546 & 59.2101 \\
11 & 4 & 2.496 & 0.702 & 3.438 & 0.833 & 0.784 & 64.9745 \\
12 & 7 & 2.485 & 0.100 & 3.435 & 1.392 & 0.590 & 29.8680 \\
13 & 2 & 2.498 & 0.134 & 3.732 & 1.262 & 0.810 & 23.8957 \\
14 & 2 & 2.449 & 0.282 & 2.684 & 1.011 & 0.535 & 43.1344 \\
15 & 2 & 2.499 & 0.102 & 2.598 & 0.766 & 0.954 & 43.3583 \\
16 & 2 & 2.500 & 0.495 & 3.608 & 1.914 & 0.480 & 23.3410 \\
\hline
\end{tabular}

Table 7 is the SPSS output for the control limit coefficient $k$. From the regression coefficients in Table 7 (2), we find that the loss incurred by the nonconformity product $M$ significantly and positively affects the control limit coefficient.

Table 8 is the SPSS output for the warning limit coefficient $w$. It may be seen from Table 8 (2) that five model parameters significantly affect the warning limit coefficient. The larger the average cost per false alarm $d$, the larger the warning limit coefficient. The occurrences frequency of the assignable cause $\theta$, the loss incurred by the nonconformity product $M$, the deviation of process standard deviation $\delta_{2}$ and the expected time to identify correct the assignable cause $t_{2}$, all negatively affect the warning limit coefficient.

The output of SPSS for the exponential weight constant $\lambda$ is recorded in Table 9. From the regression coefficients in Table 9 (2), we find that the process mean shift $\delta_{1}$ and the deviation of process standard deviation $\delta_{2}$ both significantly and positively affect the warning limit coefficient.

Table 10 is the SPSS output for loss-per-item in an average cycle process ETL. It may be seen from Table 10 (2) that the occurrences frequency of the assignable cause $\theta$, the loss incurred by the nonconformity product $M$ and the deviation of process standard deviation $\delta_{2}$ significantly and positively affect the loss-per-item in an average cycle process.

In order to intuitively illustrate the influence of the model parameters on the design parameters of the control chart and the loss cost function per unit time, we present the main effect analysis chart obtained by Minitab software in Figure 1.

\section{Comparison Study}

Assume that the distribution of the observations $Y$ from a process is normally distributed and has the mean $\mu$ and standard deviation $\sigma$. When the process is in control $\mu=\mu_{0}, \sigma=\sigma_{0}$, and when the process is out of control $\mu=\mu_{0}+\delta_{1} \sigma_{0}, \sigma=\delta_{2} \sigma_{0}$, where $\delta_{1}$ and $\delta_{2}$ are two constants, and typically $\delta_{2}$ is larger than 1 . This process can be monitored by the VSI EWMA control charts. The optimality of the joint economic model of the VSI EWMA control chart for monitoring the process mean and standard deviation is verified by comparing the following three control charts: (1) VSI EWMA control chart that is designed based on the economic model (23); (2) FSI EWMA control chart that considers quality loss and preventive maintenance; (3) VSI EWMA control chart, which is designed by using the average time to signal (ATS) as the evaluation criterion.

The parameters of the economic model $\left(a, b, \theta, d, g, t_{1}, t_{2}, \delta, C_{p m}, W, M\right)$ are shown in Table 1. The expected loss of the control chart designed by method (1) is denoted by ETL, the expected loss of the control chart designed by method (2) is denoted by $\mathrm{ETL}_{1}$, and the expected loss of the control chart designed by method (3) in cases where $\lambda=0.1$, ATS $=300,400,500$ and $\lambda=0.2$, ATS $=$ $300,400,500$ is denoted as $\mathrm{ETL}_{2}$. The parameters in method 
TABLE 4: SPSS output for sample size $n$.

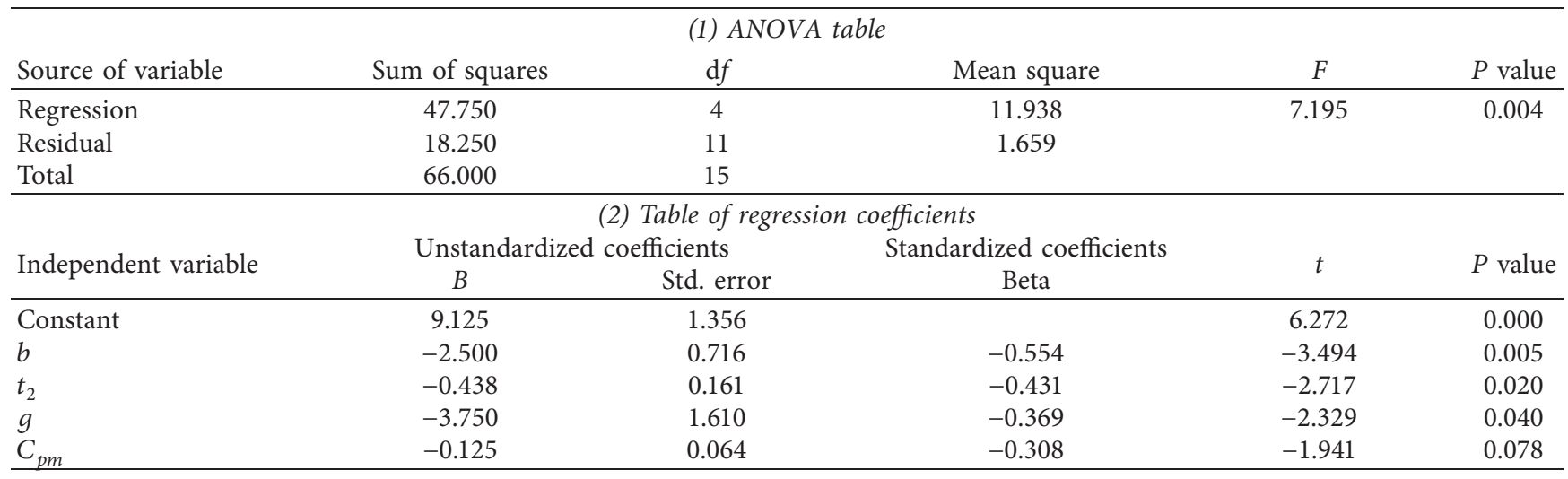

TABLE 5: SPSS output for long sampling intervals $h_{1}$.

\begin{tabular}{|c|c|c|c|c|c|}
\hline \multicolumn{6}{|c|}{ (1) ANOVA table } \\
\hline Source of variable & Sum of squares & $\mathrm{d} f$ & Mean square & $F$ & $P$ value \\
\hline Regression & 1.582 & 5 & 0.316 & 7.622 & 0.003 \\
\hline Residual & 0.415 & 10 & 0.042 & & \\
\hline Total & 1.997 & 15 & & & \\
\hline \multicolumn{6}{|c|}{ (2) Table of regression coefficients } \\
\hline \multirow{2}{*}{ Independent variable } & Unstandardi & ficients & Standardized coefficients & \multirow{2}{*}{$t$} & \multirow{2}{*}{$P$ value } \\
\hline & $B$ & Std. error & Beta & & \\
\hline Constant & 2.155 & 0.294 & & 7.334 & 0.000 \\
\hline$g$ & -0.834 & 0.255 & -0.472 & -3.275 & 0.008 \\
\hline$\delta_{2}$ & 0.416 & 0.127 & 0.471 & 3.265 & 0.008 \\
\hline$a^{2}$ & 0.086 & 0.034 & 0.366 & 2.539 & 0.029 \\
\hline$W$ & -0.060 & 0.025 & -0.339 & -2.352 & 0.040 \\
\hline$M$ & -0.044 & 0.020 & -0.314 & -2.178 & 0.054 \\
\hline
\end{tabular}

TABLE 6: SPSS output for short sampling intervals $h_{2}$.

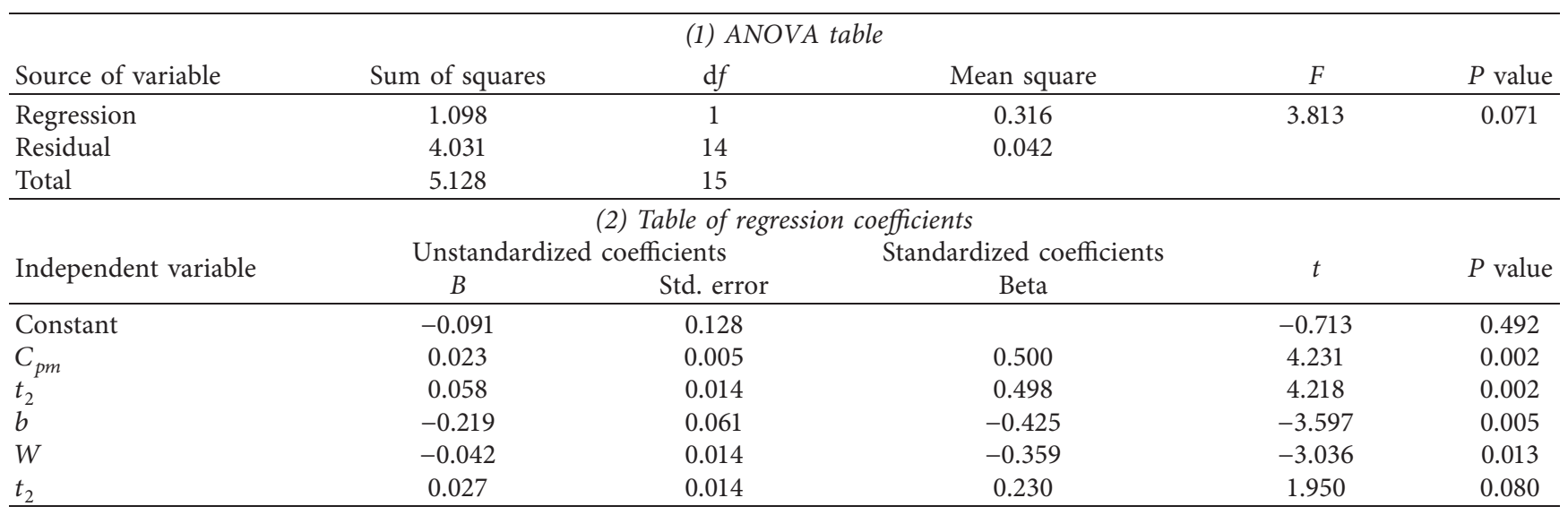

TABLE 7: SPSS output for control limit coefficient $k$.

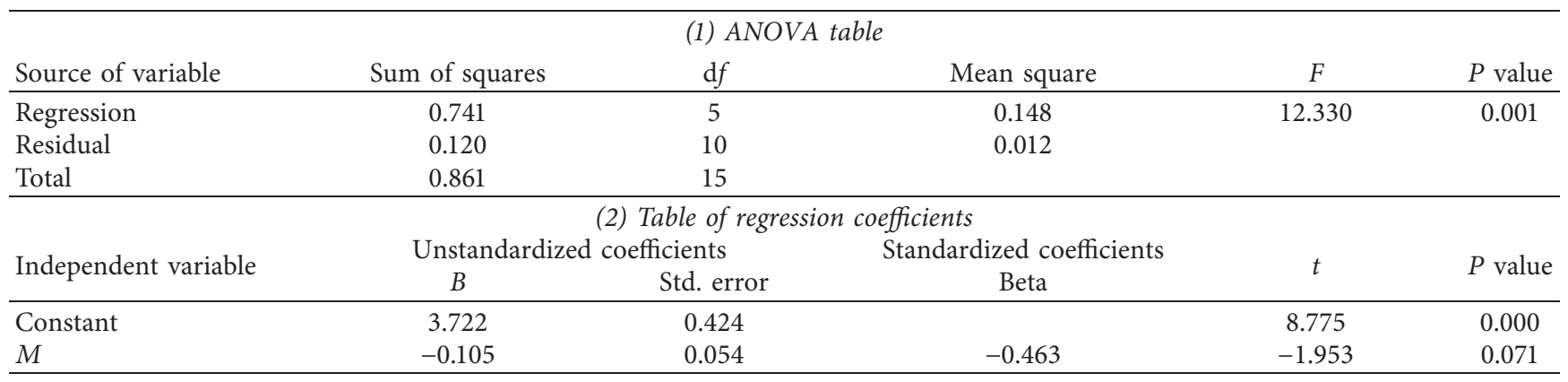


TABLE 8: SPSS output for warning limit coefficient $w$.

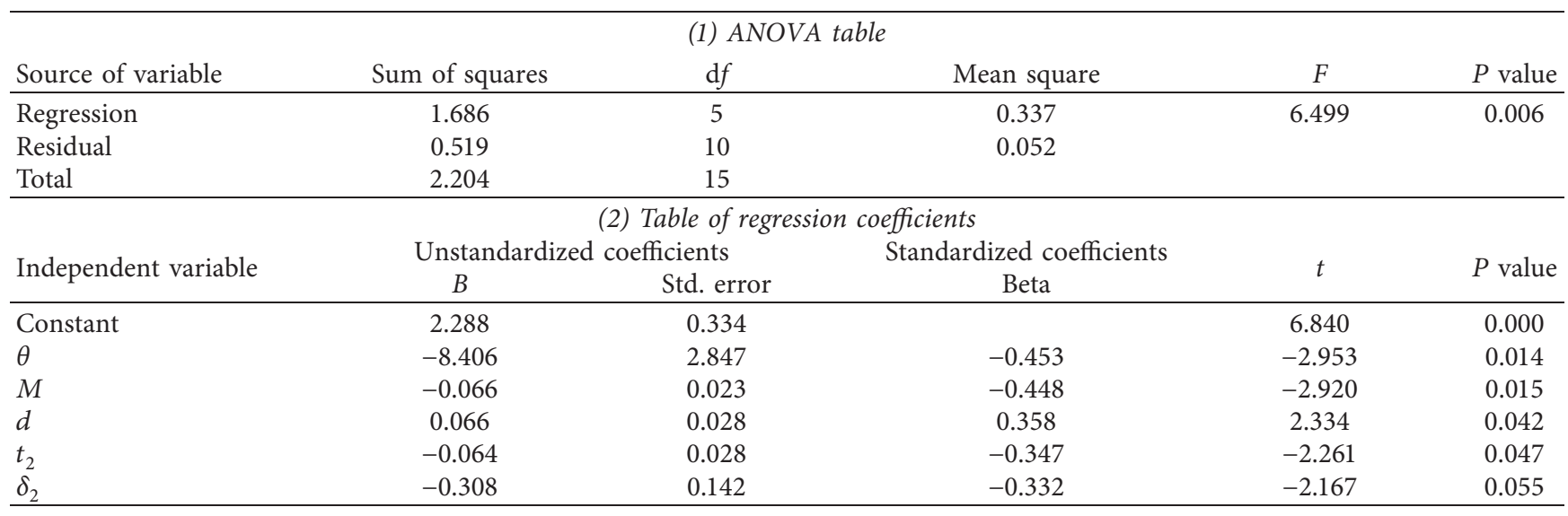

TABLE 9: SPSS output for exponential weight constant $\lambda$.

\begin{tabular}{|c|c|c|c|c|c|}
\hline \multicolumn{6}{|c|}{ (1) ANOVA table } \\
\hline Source of variable & Sum of squares & $\mathrm{d} f$ & Mean square & $F$ & $P$ value \\
\hline Regression & 0.248 & 2 & 0.124 & 11.809 & 0.001 \\
\hline Residual & 0.137 & 13 & 0.011 & & \\
\hline Total & 0.385 & 15 & & & \\
\hline \multicolumn{6}{|c|}{ (2) Table of regression coefficients } \\
\hline \multicolumn{6}{|c|}{$\begin{array}{ccc}\text { Unstandardized coefficients } & \text { Standardized coefficients } \\
B & \text { Std. error } & \text { Beta } \\
\end{array}$} \\
\hline Constant & 0.414 & 0.131 & & 3.166 & 0.007 \\
\hline$\delta_{1}$ & 0.285 & 0.064 & 0.736 & 4.452 & 0.010 \\
\hline$\delta_{2}$ & -0.200 & 0.102 & -0.322 & -1.949 & 0.073 \\
\hline
\end{tabular}

TABLE 10: SPSS output for loss-per-item in an average cycle process ETL.

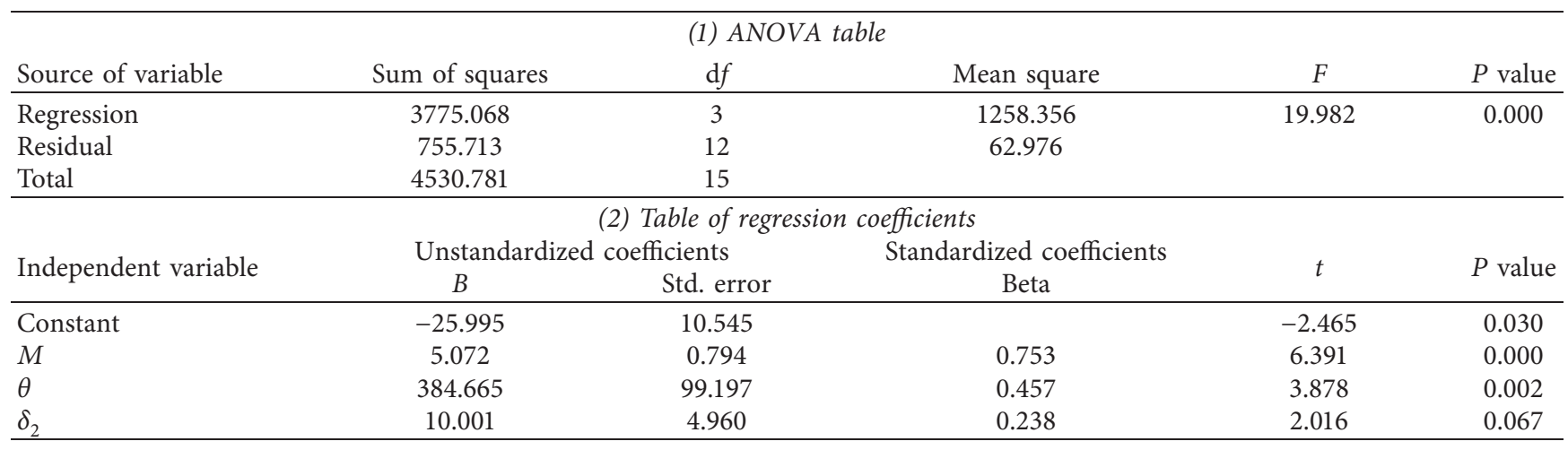

(3) are set to be $n=10, w=1.5, h_{1}=1.8, h_{2}=0.2$. The expected losses from 16 orthogonal tests were recorded in Table 11.

First, the economic advantages of the dynamic control chart designed by method (1) and the static control chart designed by method (2) are investigated. As can be seen from Table 11, in all the trials considered here, ETL are less than ETL $_{1}$. For example, in the third test, the expected loss of VSI EWMA control chart designed by method (1) is 38.6429, and that of static EWMA control chart designed by method (2) is 40.1353 , which is larger than that by method (1). The average values of 16 experiments were calculated and recorded on the table. The average value of ETL is 39.5824, which is less than the average value of $\mathrm{ETL}_{1}$ 41.8791. That is to say, VSI EWMA control charts designed by the joint economic model (23) are better than FSI EWMA control charts considering quality loss and preventive maintenance.

Then, the economic efficiency of the dynamic control chart designed by method (1) and method (3) is compared. Table 4 shows that, for the 16 tests considered here, ETL are less than $\mathrm{ETL}_{2}$; for example, in the second test, the corresponding ETL of the VSI EWMA control chart designed by the joint economic model (23) is 38.8650, while ETL $\mathrm{ET}_{2}$ of the VSI EWMA control chart that uses the average time to signal 


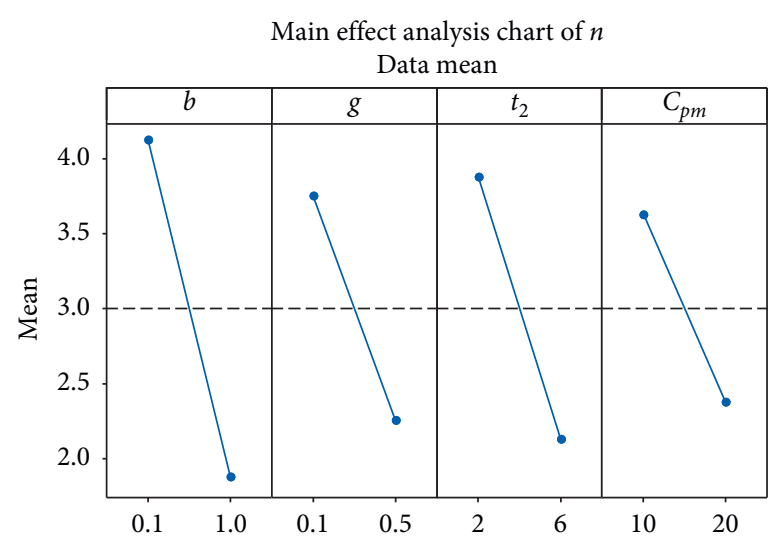

(a)

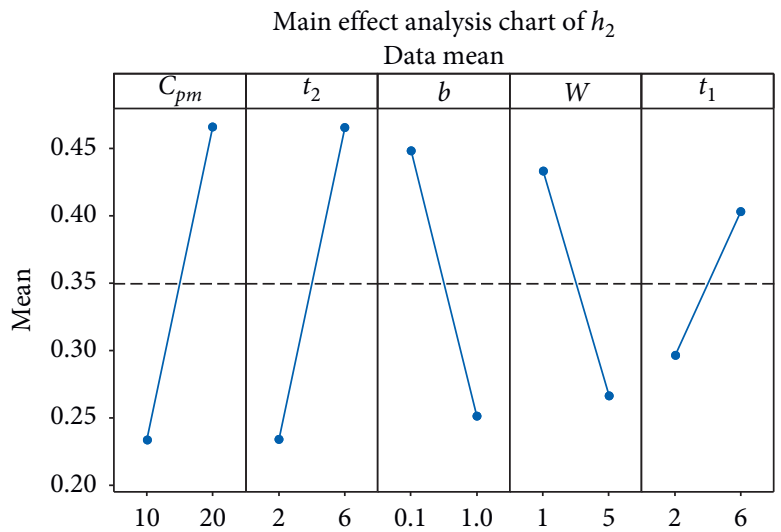

(c)

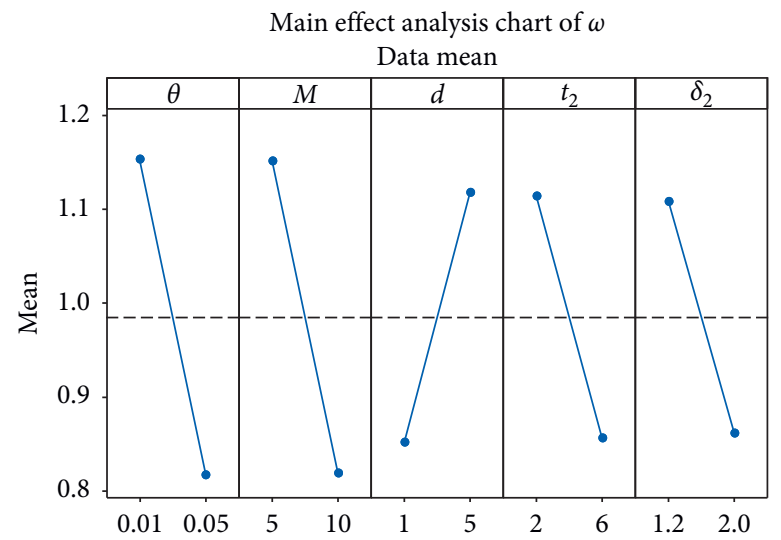

(e)

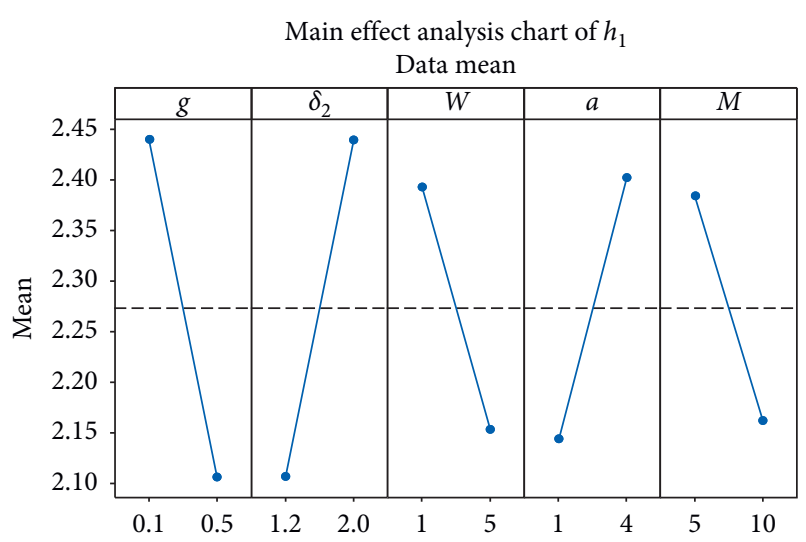

(b)

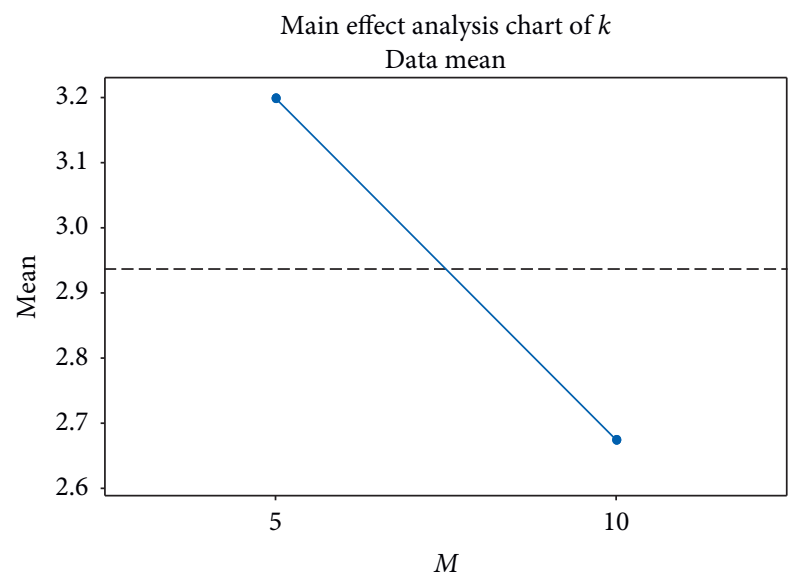

(d)

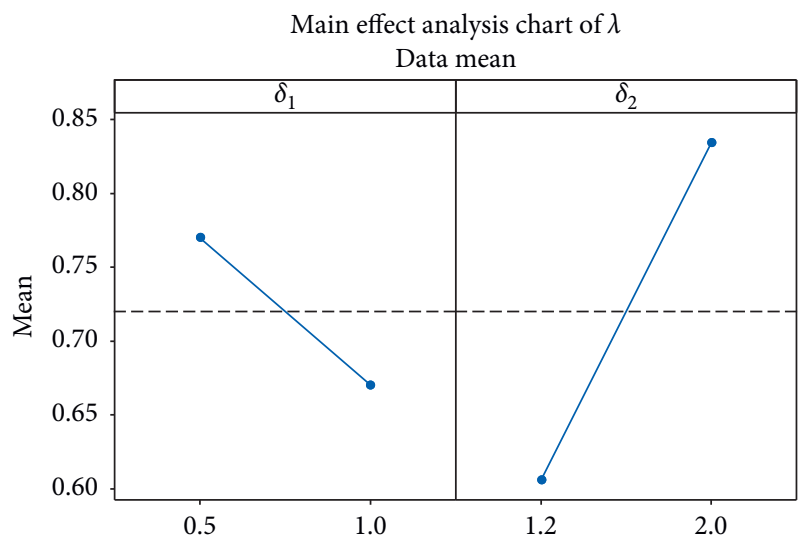

(f)

FIgURE 1: Continued. 


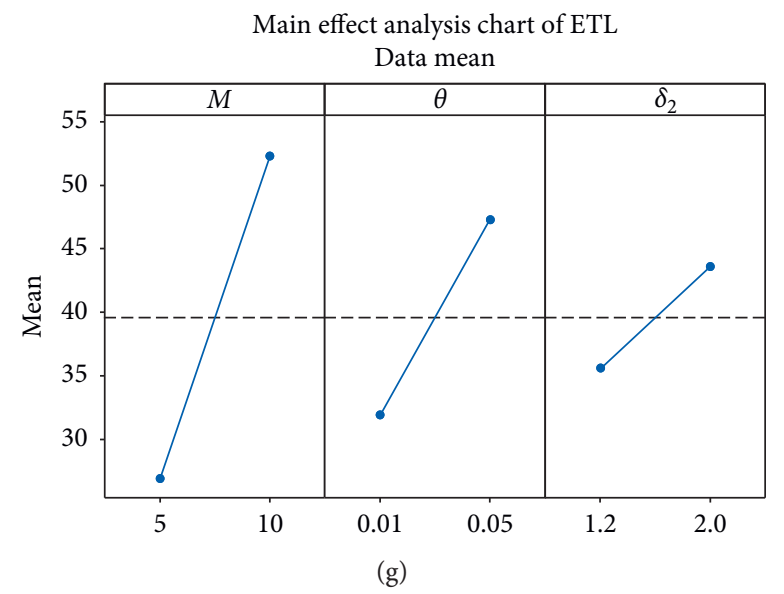

FIGURE 1: The main effect analysis chart of the design parameter $\left(n, h_{1}, h_{2}, k, w, \lambda\right)$ and the loss-per-item in an average cycle process ETL.

TABLE 11: Comparison study results.

\begin{tabular}{|c|c|c|c|c|c|c|c|c|}
\hline \multirow{2}{*}{ Trial } & \multirow{2}{*}{ ETL } & \multirow{2}{*}{$\mathrm{ETL}_{1}$} & \multicolumn{3}{|c|}{$\operatorname{ETL}_{2}(\lambda=0.1)$} & \multicolumn{3}{|c|}{$\operatorname{ETL}_{2}(\lambda=0.2)$} \\
\hline & & & $\mathrm{ATS}=300$ & $\mathrm{ATS}=400$ & $\mathrm{ATS}=500$ & $\mathrm{ATS}=300$ & $\mathrm{ATS}=400$ & $\mathrm{ATS}=500$ \\
\hline 1 & 18.3545 & 19.7863 & 20.8468 & 21.2379 & 21.5315 & 21.0356 & 21.5042 & 21.8744 \\
\hline 2 & 38.8650 & 41.0324 & 43.5259 & 43.7087 & 43.8204 & 42.7734 & 42.9482 & 43.0610 \\
\hline 3 & 38.6429 & 40.1353 & 41.5356 & 42.0784 & 42.4875 & 41.7562 & 42.4511 & 43.0059 \\
\hline 4 & 25.5207 & 26.2378 & 26.7211 & 26.9762 & 27.1470 & 26.5787 & 26.8287 & 27.0029 \\
\hline 5 & 25.5298 & 27.9657 & 29.6506 & 30.6041 & 31.3239 & 30.1312 & 31.0476 & 31.7352 \\
\hline 6 & 83.3284 & 86.4539 & 90.6725 & 90.8758 & 91.0152 & 89.1627 & 89.4173 & 89.6065 \\
\hline 7 & 46.5759 & 49.5872 & 53.7554 & 54.9432 & 55.8342 & 54.2712 & 55.5815 & 56.5726 \\
\hline 8 & 32.7368 & 35.4285 & 37.5885 & 37.7486 & 37.8551 & 36.3964 & 36.5820 & 36.7161 \\
\hline 9 & 35.9818 & 37.8320 & 39.1900 & 39.7338 & 40.1259 & 38.8800 & 39.4790 & 39.9293 \\
\hline 10 & 59.2101 & 63.5478 & 66.1703 & 66.7910 & 67.2486 & 65.6531 & 66.5040 & 67.1692 \\
\hline 11 & 64.9745 & 68.8659 & 73.8814 & 74.3845 & 74.7411 & 72.6392 & 73.2223 & 73.6590 \\
\hline 12 & 29.8680 & 33.5379 & 35.0103 & 35.5611 & 35.9727 & 34.9695 & 35.6383 & 36.1588 \\
\hline 13 & 23.8957 & 24.5783 & 25.3010 & 25.4679 & 25.5786 & 25.1192 & 25.2852 & 25.4004 \\
\hline 14 & 43.1344 & 45.1238 & 46.3203 & 46.8196 & 47.1733 & 46.2062 & 46.8030 & 47.2558 \\
\hline 15 & 43.3583 & 45.4632 & 46.5807 & 46.7288 & 46.8235 & 45.9994 & 46.1580 & 46.2673 \\
\hline 16 & 23.3410 & 24.4891 & 25.4577 & 25.9136 & 26.2384 & 25.6079 & 26.1007 & 26.4702 \\
\hline \multirow{2}{*}{ Mean standardization } & 39.5824 & 41.8791 & 43.8880 & 44.3483 & 44.6823 & 43.5737 & 44.0969 & 44.4928 \\
\hline & 1 & 1.0580 & 1.1088 & 1.1204 & 1.1288 & 1.1008 & 1.1141 & 1.1241 \\
\hline
\end{tabular}

as the evaluation criterion is greater in cases when $\lambda=0.1$, ATS $=300,400,500$ and $\lambda=0.2$, ATS $=300,400,500$. The average values of 16 experiments were calculated and presented on the tables. The average values of ETL are 39.5824, which is much smaller than the average values of $\mathrm{ETL}_{2}$ in several cases. That is to say, VSI EWMA control charts designed by the joint economic model are superior to VSI EWMA control charts designed by the average time to signal as the evaluation criterion in each test.

In the last line of the table, standardized values of the average values of the three control charts are presented; i.e., the average value of each control chart was divided by 39.5824. For example, when $\lambda=0.1$, ATS $=400$, the standardized value of the average values of $\mathrm{ETL}_{2}$ is 1.1204 . It shows that ETL $\mathrm{EL}_{2}$ is 1.1204 times of ETL; that is to say, VSI EWMA control charts designed by the joint economic model are 1.1204 times better than the model that uses ATS as evaluation criteria; $\mathrm{ETL}_{1}$ is 1.0580 times better than ETL; that is, VSI EWMA control charts designed by the joint economic decision model are 1.0931 times better than the FSI EWMA control chart.

Therefore, the comparison study results show that the VSI EWMA control charts designed by the joint economic model have a less expected loss and are superior to the FSI EWMA control charts designed by the joint economic model and the VSI EWMA control chart that uses ATS as evaluation criteria.

\section{Conclusion}

To determine the values of the six design parameters of the VSI EWMA control charts, such that loss-per-item in an average cycle process is minimized, we developed an economic design of the VSI EWMA control chart for monitoring the mean and standard deviation under preventive maintenance and Taguchi's loss function. The method is illustrated using an example, and GA is employed to search for the optimal parameters of the 
economic design. The effect of model parameters on the optimal parameters can be obtained from a sensitivity analysis of the economic model. Finally, the comparison study results show that the VSI EWMA control charts designed by the joint economic model is superior to the FSI EWMA control charts designed by the joint economic model and the VSI EWMA control chart that uses ATS as evaluation criteria. In this paper, we only consider cases where observations are univariate. In many applications, multivariate performance variables are involved. Thus, joint economic design of control charts for monitoring multivariate quality characteristics and preventive maintenance will need to be explored in future research.

In the traditional tests under classical statistics, it is assumed that all observations are crisp in the population or the sample. But, the data obtained from the complex system may not be determined, exact, and certain. In this case, classical statistics are no longer suitable, which are replaced by Neutrosophic statistics. Neutrosophic statistics is used when the data is obtained from the complex process. Almarashi and Aslam [50] proposed the control chart for monitoring the Gamma distributed product under neutrosophic statistics using resampling scheme. In consequence of the existing Anderson-Darling test that cannot be applied for testing the assumption of the Weibull distribution, Aslam [51] presented the Anderson-Darling test under neutrosophic statistics. Khan et al. [52] presented new attribute control charts for monitoring the blood components under the neutrosophic statistics. The applications of these control charts demonstrate that the proposed control charts are quite effective, adequate, flexible, and informative for monitoring the blood components under uncertain environment. Aslam [53] designed a control chart for neutrosophic exponentially weighted moving average (NEWMA) using repetitive sampling, and the application of the proposed NEWMA chart is given to monitoring road traffic crashes (RTC). From these literatures, it is observed that the control chart designed by Neutrosophic statistics is an efficient addition in the tool kit of the quality control personnel; thence, when the data is obtained from the complex process, the proposed chart in this paper can be extended for neutrosophic statistics in the future.

\section{Data Availability}

The data used to support the findings of this study are included within the article.

\section{Conflicts of Interest}

The authors declare that they have no conflicts of interest.

\section{Acknowledgments}

This research was supported by the National Science Foundation of China under Grants 71701188 and 71902138, Humanities and Social Sciences Research Program of the Ministry of Education of China under Grant 21YJC630151, China Postdoctoral Science Foundation under Grant
2016M601266, Program for Science and Technology Innovation in Universities of Henan Province under Grant 19HASTIT032, and Program for Science and Technology Research of Henan Province under Grant 202102310638.

\section{References}

[1] D. C. Montgomery, Introduction to Statistical Quality Control, John Wiley \& Sons, Hoboken, NJ, USA, 2007.

[2] M. Abouei Ardakan, A. Zeinal Hamadani, M. Sima, and M. Reihaneh, "A hybrid model for economic design of MEWMA control chart under maintenance policies," The International Journal of Advanced Manufacturing Technology, vol. 83, no. 9-12, pp. 2101-2110, 2016.

[3] A. J. Duncan, "The economic design of x-bar charts used to maintain current control of a process," Journal of the American Statistical Association, vol. 52, pp. 228-242, 1956.

[4] D. C. Montgomery, "The economic design of control charts: a review and literature survey," Journal of Quality Technology, vol. 12, pp. 75-87, 1980.

[5] T. J. Lorenzen and L. C. Vance, "The economic design of control charts: a unified approach," Technometrics, vol. 28, pp. 3-10, 1986.

[6] E. M. Saniga, "Economic statistical control-chart designs with an application to $X$-bar and $R$ charts," Technometrics, vol. 31, pp. 313-320, 1989.

[7] B. C. Franco, G. Celano, P. Castagliola, and A. F. B. Costa, "Economic design of Shewhart control charts for monitoring autocorrelated data with skip sampling strategies," International Journal of Production Economics, vol. 151, pp. 121-130, 2014.

[8] F. Naderkhani and V. Makis, "Economic design of multivariate Bayesian control chart with two sampling intervals," International Journal of Production Economics, vol. 174, pp. 29-42, 2017.

[9] S. F. Costa, "Economic statistical design of ARMA control chart through a modified fitness-based self-adaptive differential evolution," Computers \& Industrial Engineering, vol. 105, pp. 174-189, 2017.

[10] A. Amiri, A. Moslemi, and M. H. Doroudyan, "Robust economic and economic-statistical design of EWMA control chart," The International Journal of Advanced Manufacturing Technology, vol. 78, no. 1-4, pp. 511-523, 2015.

[11] A. Saghaei, S. M. T. F. Ghomi, and S. Jaberi, "Economic design of EWMA control chart based on measurement error using genetic algorithm," Quality Reliability Engineering International, vol. 30, no. 8, pp. 1153-1163, 2014.

[12] C.-Y. Chou, C.-H. Chen, and H.-R. Liu, "Economic design of EWMA charts with variable sampling intervals," Quality \& Quantity, vol. 40, no. 6, pp. 879-896, 2006.

[13] L. Xue and Y. M. Liu, "Economic design of EWMA charts for non-normal data using variable sampling policy," Journal of Applied Statistics and Management, vol. 30, no. 5, pp. 863871, 2011.

[14] C. Li, A. Mukherjee, Q. Su, and M. Xie, "Robust algorithms for economic designing of a nonparametric control chart for abrupt shift in location," Journal of Statistical Computation and Simulation, vol. 86, no. 2, pp. 306-323, 2016.

[15] C. Li, A. Mukherjee, Q. Su, and M. Xie, “Optimal design of a distribution-free quality control scheme for cost-efficient monitoring of unknown location," International Journal of Production Research, vol. 54, no. 24, pp. 7259-7273, 2016.

[16] C. Li and A. Mukherjee, "Nonparametric cost-minimized Shewhart-type process monitoring with restricted false alarm 
probability," Quality and Reliability Engineering International, vol. 35, no. 6, pp. 1846-1865, 2019.

[17] C. Li and A. Mukherjee, "Two economically optimized nonparametric schemes for monitoring process variability," Quality and Reliability Engineering International, vol. 37, pp. 1939-1955, 2021.

[18] M. Aslam, P. Jeyadurga, S. Balamurali, M. Azam, and A. ALMarshadi, "Economic determination of modified multiple dependent state sampling plan under some lifetime distributions," Journal of Mathematics, vol. 2021, Article ID 7470196, 13 pages, 2021.

[19] M. Aslam, S. Balamurali, C.-H. Jun, and B. Hussain, "Design of SkSP-R variables sampling plans," Revista Colombiana de Estadística, vol. 38, no. 2, pp. 413-429, 2015.

[20] M. S. Fallahnezhad, S. T. A. Niaki, and M. A. Vahdat Zad, “A new economic design of acceptance sampling models using bayesian inference," Accreditation and Quality Assurance, vol. 8, pp. 187-195, 2012.

[21] M. S. Fallahnezhad, A. A. Yazdi, P. Abdollahi, and A. Muhammad, "Design of economic optimal double sampling design with zero acceptance numbers," Journal of Quality Engineering and Production Optimization, vol. 2, no. 1, pp. 45-56, 2015.

[22] J. Hussain, A. R. Mughal, M. K. Pervaiz, M. Aslam, and A. Rehman, "Economic reliability group acceptance sampling plans for lifetimes following a generalized exponential distribution," Electronic Journal of Applied Statistical Analysis, vol. 4, no. 2, pp. 124-130, 2011.

[23] M. S. F. Nezhard and S. T. A. Niaki, "A new acceptance sampling design using Bayesian modeling and backward induction," IJE Transactions C: Aspects, vol. 25, no. 1, pp. 45-54, 2012.

[24] M. Ben-Daya, "Integrated production maintenance and quality model for imperfect processes," IIE Transactions, vol. 31, no. 6, pp. 491-501, 1999.

[25] S. El-Ferik, "Economic production lot-sizing for an unreliable machine under imperfect age-based maintenance policy," European Journal of Operational Research, vol. 186, pp. 150163, 2008.

[26] M. Radhoui, N. Rezg, and A. Chelbi, "Integrated maintenance and control policy based on quality control," Computers \& Industrial Engineering, vol. 58, pp. 443-451, 2010.

[27] M. Zohreh and N. Rassoul, "An integrated model based on statistical process control and maintenance," Computers \& Industrial Engineering, vol. 61, pp. 1245-1255, 2011.

[28] K. Linderman, K. E. McKone-Sweet, and J. C. Anderson, “An integrated systems approach to process control and maintenance," European Journal of Operational Research, vol. 164, no. 2, pp. 324-340, 2005.

[29] W. H. Zhou and G. L. Zhu, "Economic design of integrated model of control chart and maintenance management," Mathematical and Computer Modelling, vol. 47, pp. 13891395, 2008.

[30] Y. Xiang, "Join optimization of control chart and preventive maintenance policies: a discrete-time Markov chain approach," European Journal of Operational Research, vol. 229, pp. 382-390, 2013.

[31] D. Shrivastava, M. S. Kulkarni, and P. Vrat, "Integrated design of preventive maintenance and quality control policy parameters with CUSUM chart," International Journal of Advanced Manufacture Technology, vol. 82, pp. 2101-2112, 2016.

[32] B. Bouslah, A. Gharbi, and R. Pellerin, "Integrated production, sampling quality control and maintenance of deteriorating production systems with AOQL constraint," Omega, vol. 61, pp. 110-126, 2016.

[33] A. Salmasnia, B. Abdzadeh, and M. Namdar, "A joint design of production run length, maintenance policy and control chart with multiple assignable causes," Journal of Manufacturing Systems, vol. 42, pp. 44-56, 2017.

[34] Q. Wan, Y. Z. Wu, W. h. Zhou, and X. H. Chen, "Economic design of an integrated adaptive synthetic $X$-bar chart and maintenance management system," Communications in Statistics-Theory and Methods, vol. 47, no. 11, pp. 2625-2642, 2018.

[35] A. F. B. Costa and M. A. G. Machado, "A side-sensitive synthetic chart combined with a VSS $\bar{X}$ chart," Computers \& Industrial Engineering, vol. 91, pp. 205-214, 2016.

[36] Z. T. Kosztyán and A. I. Katona, "Risk-based X-bar chart with variable sample size and sampling interval," Computers \& Industrial Engineering, vol. 120, pp. 308-319, 2018.

[37] G. Nenes, K. A. Tasias, and G. Celano, "A general model for the economic-statistical design of adaptive control charts for processes subject to multiple assignable causes," International Journal of Production Research, vol. 53, pp. 2146-2164, 2015.

[38] S. Panagiotidou and G. Nenes, "An economically designed, integrated quality and maintenance model using an adaptive Shewhart chart," Reliability Engineering and System Safety, vol. 94, pp. 732-741, 2009.

[39] M. R. Reynolds Jr., "Optimal variable sampling interval control charts," Sequential Analysis, vol. 8, pp. 361-379, 1989.

[40] M. R. Reynolds Jr., "Variable sampling interval control charts with sampling at fixed times," IIE Transactions, vol. 28, pp. 497-510, 1996.

[41] H. Safe, R. Kazemzadeh, and K. Y. A. Gholipour, "Markov chain approach for double-objective economic statistical design of the variable sampling interval control chart," Communications in Statistics-Theory and Methods, vol. 47, no. 2, pp. 277-288, 2018.

[42] R. A. Sanusia, M. Riazb, N. A. Adegokec, and M. Xie, "A EWMA monitoring scheme with a single auxiliary variable for industrial processes," Computers \& Industrial Engineering, vol. 114, pp. 1-10, 2017.

[43] W. L. Teoh, J. Chong, M. B. Khoo, P. Castagliola, and W. C. Yeong, "Optimal designs of the variable sample size $\bar{X}$ chart based on median run length and expected median run length," Quality and Reliability Engineering International, vol. 33, no. 1, pp. 121-134, 2017.

[44] L. Xue, "EWMA control chart with variable sampling intervals for monitoring process mean and standard deviation," Journal of Applied Statistical and Management, vol. 34, no. 1, pp. 93-99, 2015.

[45] W. S. Chen, F. J. Yu, R. S. Guhand, and Y. H. Lin, "Economic design of $\mathrm{x}$-bar control charts under preventive maintenance and Taguchi loss functions," Journal of Applied Operational Research, vol. 3, no. 2, pp. 103-109, 2011.

[46] A. S. Safaei, R. B. Kazemzadeh, and S. T. A. Niaki, "Multiobjective economic statistical design of $X$-bar control chart considering Taguchi loss function," International Journal of Advanced Manufacture Technology, vol. 59, pp. 1091-1101, 2012.

[47] I. Sultana, I. Ahmed, A. Azeem, and N. R. Sarker, "Economic design of exponentially weighted moving average chart with variable sampling interval at fixed times scheme incorporating Taguchi loss function," International Journal of Industrial and Systems Engineering, vol. 29, no. 4, pp. 428-452, 2018. 
[48] M. T. Chao and S. W. Cheng, "Semicircle control chart for variables data," Quality Engineering, vol. 8, no. 3, pp. 441-446, 1996.

[49] G. Chen, S. W. Cheng, and H. Xie, "A new EWMA control chart for monitoring both location and dispersion," Quality Technology \& Quantitative Management, vol. 1, no. 2, pp. 217-231, 2004.

[50] A. M. Almarashi and M. Aslam, "Process monitoring for gamma distributed product under neutrosophic statistics using resampling scheme," Journal of Mathematics, vol. 2021, Article ID 6635846, 12 pages, 2021.

[51] M. Aslam, "A new goodness of fit test in the presence of uncertain parameters," Complex \& Intelligent Systems, vol. 7, no. 1, pp. 359-365, 2021.

[52] N. Khan, A. Aslam, P. Jeyadurga, and S. Balamurali, "Monitoring of production of blood components by attribute control chart under indeterminacy," Scientifc Reports, vol. 11, p. 922, 2021.

[53] A. Aslam, "Monitoring the road traffic crashes using NEWMA chart and repetitive sampling," International Journal of Injury Control and Safety, vol. 28, no. 1, pp. 39-45, 2020 . 